\title{
Effects of At2 Receptor Agonist Novokinin on Oxidative Stress, Inflammation and Infarct Size Due to Myocardial Ischemia-Reperfusion
}

\author{
Esra Gunduz ${ }^{1}$ Engin Sahna ${ }^{2}$ \\ ${ }^{1}$ Bitlis Eren University, Bitlis, Turkey \\ ${ }^{2}$ Firat University, Elazı̆̆, Turkey \\ Email: egunduz@beu.edu.tr
}

How to cite this paper: Gunduz, E. and Sahna, E. (2017) Effects of At2 Receptor Agonist Novokinin on Oxidative Stress, Inflammation and Infarct Size Due to Myocardial Ischemia-Reperfusion. J. Biomedical Sci-ence and Engineering, 10, 257-272. https://doi.org/10.4236/jbise.2017.105020

Received: December 1, 2016

Accepted: May 21, 2017

Published: May 24, 2017

Copyright $\odot 2017$ by authors and Scientific Research Publishing Inc. This work is licensed under the Creative Commons Attribution International License (CC BY 4.0).

http://creativecommons.org/licenses/by/4.0/ (c) (i) Open Access

\begin{abstract}
Aim: Ischemia and reperfusion (IR) injury is a serious problem that is occurred during thrombolytic therapy, organ transplantation, coronary angioplasty, and cardiopulmonary bypass. There is an increase in the number of AT2 receptors in some pathological conditions such as cardiac hypertrophy, myocardial infarction, congestive heart failure. This study was designed to investigate the effects AT2 receptor agonist Novokinin on infarct size, caveolin-1 (CAV-1), HSP90, ADMA, NADPH oxidase and Rhokinase associated to endothelial dysfunction and oxidative stress, and NFKB and TLR-4 levels induced by inflammation on myocardial IR. Methods: The experimental groups: Sham (C), Novokinin (N), IR and IRN. Novokinin was performed with infusion pump before ischemia, and during IR. The left main coronary artery was occluded for 30 minutes ischemia followed by 120 minutes reperfusion in anesthetized rats. CAV-1, HSP90, and NFאB levels were measured by the quantitative reverse transcriptase polymerase chain reaction (qRT-PCR), ADMA, TLR-4, NADPH oxidase, and Rhokinase levels were measured by ELISA, infarct size was measured by ImageJ, an image analysis software, in the heart tissue. Results: NFkB, HSP90, NADPH oxidase and TLR-4 levels increased with IR and significantly decreased with Novokinin. CAV-1 levels were not different between the groups. ADMA and Rhokinase levels were increased due to IR but decreased with Novokinin. Novokinin reduced infarct size due to IR. Conclusion: Our results showed that, ADMA, HSP90, NFKB, TLR-4, Rhokinase, and NADPH oxidase levels play important roles on IR injury. AT2 receptor agonist Novokinin may affect positively oxidative changes, inflammation, and endothelial function in myocardial IR injury.
\end{abstract}

\section{Keywords}

Ischemia-Reperfusion, AT2 Receptor, ADMA, NFkB, HSP90 


\section{Introduction}

Ischemic heart disease remains one of the most important causes of morbidity and mortality throughout the world [1]. The most common form is "coronary atherosclerotic heart disease" and the coronary blood flow to myocardium due to atherosclerotic plaques and vasospasm is reduced [2]. Ischemia and reperfusion (IR) injury is a serious problem that is occurred during a variety of medical and surgical procedures, such as thrombolytic therapy, organ transplantation, coronary angioplasty, and cardiopulmonary bypass [3]. Endothelial dysfunction, oxidative stress and inflammation are among the most common mechanisms of IR injury [4].

Nuclear factor kappa-B $(\mathrm{NF \kappa B})$ is responsible for the production of inflammatory genes redox-sensitive transcription factors, which activate in response to oxidative stress. NFkB activation stimulates the expression of proinflammatory cytokines. NFkB pathway is involved in the pathological process and activates cell death pathways [5].

Toll-like receptor 4 (TLR-4) was involved in the inflammatory response of myocardial IR injury, which could promote the formation of active oxygen free radicals and also activate many cytokine [6].

The heat shock protein 90 (HSP90) secretion regulates endothelial nitric oxide synthase (eNOS) activity, modulates subsequent nitric oxide (NO) production and provides myocardial protection against IR damage [7].

Asymmetrical dimethyl arginine (ADMA) is an eNOS inhibitor. Increased ADMA levels caused by oxidative stress, increases the production of reactive oxygen species and activates Renin-Angiotensin-Aldosteron-System (RAAS) [4]. ADMA is regarded as a marker of cardiovascular risk.

Caveolin-1 (CAV-1) is regulatory of NO, eNOS and calcium $\left(\mathrm{Ca}^{2+}\right)$ in cardiovascular endothelium. In addition, the effects of CAV-1 via NO in myocardial IR is protective for the heart and the CAV-1 deficiency is exacerbated cardiac dysfunction reduces the survival rate [8].

Rhokinase is one enzyme that is activated during IR. Inhibition of Rhokinase causes eNOS activation, reduction vascular inflammation and atherosclerosis [9]. In addition, it is believed that inhibition of Rhokinase may be a useful therapeutic target in cardiovascular disease or associated risk factors in individuals [10].

A common result of active mechanisms during IR period is necrosis of cardiac cells [11]. Releasing the cell contents to intracellular space after cell death causes inflammation. Macrophages and neutrophils migrate to the necrotic tissue and then phagocytose necrotic tissue. Thus, inflammation is an important sign of necrosis.

In the cardiovascular system, Angiotensin II (AII) generated during oxidative stress and vascular inflammation leads to endothelial dysfunction, cell growth and inflammation by activating NADPH oxidase [12] [13]. A large part of cardiovascular effects of AII are regulated through Angiotensin type 1 receptor (AT1) receptors. Tissue RAAS activity and AT1 receptor synthesis are increased 
after hypertensive hypertrophy, cardiac insufficiency and myocardial infarction (MI] [14]. It is known that Angiotensin type 2 receptor (AT2) receptors balanced the effects of AT1 and had antagonistic effect to AT1. AT2 receptor inhibits growth and has antihypertrophic and proapoptotic properties [15]. There is an increase in the number of AT2 receptors in pathological conditions such as cardiac hypertrophy, MI, congestive heart failure [16].

Novokinin (Arg-Pro-Leu-Lys-Pro-Trp), having affinity for the AT2 receptor, is a potent vasorelaxing and hypotensive peptide designed based on the structure of ovokinin [2]-[7], a bioactive peptide derived from ovalbumin [17].

To our knowledge, the effects of Novokinin on NFאB, TLR-4, HSP90, ADMA, CAV-1, NADPH oxidase and Rhokinase levels, and infarct size are not known in cardiac IR injury. In this study, we aimed to investigate the influence of AT2 receptor agonist Novokinin on NFKB and TLR-4 levels induced by inflammation, HSP90, ADMA, CAV-1, NADPH oxidase and Rhokinase associated due to endothelial dysfunction and oxidative stress, and infarct size in a rat model of myocardial IR injury.

\section{Methods}

\subsection{Experimental Groups}

Twenty-eight male Sprague Dawley rats weighing $200-250 \mathrm{~g}$ were placed in a quiet, temperature $\left(21^{\circ} \mathrm{C} \pm 1^{\circ} \mathrm{C}\right)$ and humidity $(60 \% \pm 5 \%)$ controlled room in which a $12-12 \mathrm{~h}$ light-dark cycle was maintained. All experiments were performed between 9:00 and 17:00 h. All experiments in this study were performed in accordance with the guidelines for animal research from the National Institutes of Health and were approved by the Committee on Animal Research at Firat University, Elazig (FUBAP TF.12.90).

\subsection{Experiment Plan and Drug Applications}

Rats were divided into four groups of seven rats each:

Group 1 (Sham, C) received $0.09 \%$ normal saline with infusion pump via cannula were placed the jugular vein under general anesthesia for 150 minutes at $2 \mathrm{ml} / \mathrm{min}$. The chest was opened and every step carried out except ligation.

Group 2 (Novokinin, $\boldsymbol{N}$ ) received Novokinin $(0.05 \mathrm{mg} / \mathrm{kg}$ ) [18] with infusion pump via cannula were placed the jugular vein under general anesthesia for 150 minutes at $2 \mathrm{ml} / \mathrm{min}$. The chest was opened and every step carried out except ligation.

Group 3 (Ischemia-reperfusion, IR) received 0.09\% normal saline with infusion pump via cannula were placed the jugular vein under general anesthesia for 30 minutes before ischemia and during IR at $2 \mathrm{ml} / \mathrm{min}$. This group was subjected to the myocardial IR.

Group 4 (Ischemia-reperfusion+Novokinin, IRN) received Novokinin $(0.05 \mathrm{mg} / \mathrm{kg})$ with infusion pump via cannula were placed the jugular vein under general anesthesia for 30 minutes before ischemia and during IR at $2 \mathrm{ml} / \mathrm{min}$. 
This group was subjected to the myocardial IR.

\subsection{Ischemia-Reperfusion Procedure}

Rats were anesthetized with urethane $(1.2-1.4 \mathrm{~g} / \mathrm{kg})$ administered intraperitoneally. The trachea was cannulated for artificial respiration. The chest was opened by a left thoracotomy. Positive-pressure artificial respiration was started immediately with room air, using a volume of $1.5 \mathrm{~mL} / 100 \mathrm{~g}$ body weight at a rate 60 beats/min to maintain normal $\mathrm{pCO}_{2}, \mathrm{pO}_{2}$, and $\mathrm{pH}$ parameters. A 6/0 silk suture attached to a $10 \mathrm{~mm}$ micropoint reverse-cutting needle was quickly placed under the left main coronary artery. The artery was occluded for $30 \mathrm{~min}$ and then reperfused for $120 \mathrm{~min}$.

\subsection{Evaluation of Hemodynamic Parameters}

Blood Pressure (BP) measurement were carried using direct and indirect methods. Indirect BP was performed on conscious rat with tail-cuff method by using MAY BPHR 9610-PC TAIL CUFF before one day from experiments. On the day of experiment, BP was monitored from the carotid artery by a Harvard model 50 - 8952 transducer (Harvard Apparatus, Inc., Shrewsbury, Massachusetts, USA) and displayed on a Harvard Universal pen recorder (Harvard Apparatus, Inc.). IR groups, BP and electrocardiogram (ECG) were monitored during stabilization period until ischemia, at the onset and end of ischemia and at the onset, first and second hours of reperfusion.

\subsection{Evaluation of Tissue Death}

The heart was quickly removed and was flushed with saline at room temperature for $60 \mathrm{~s}$. The heart was frozen and cut into $2 \mathrm{~mm}$ transverse slices. The slices were incubated in $1 \%$ triphenyl tetrazolium chloride (TTC) in pH 7.4 buffer at $37^{\circ} \mathrm{C}$ for $20 \mathrm{~min}$. TTC stains living tissue a deep red color while necrotic tissue is TTC negative and appears tan. The volume of infarct size was determined by planimetry of each tracing and multiplying by the slice thickness.

\subsection{Genetic Analysis}

$2 \mathrm{~mm}$ transverse slices were included in $1.5 \mathrm{ml}$ Eppendorf tubes containing RNA later solution. It was waited at $+4^{\circ} \mathrm{C}$ afterward a night, it was stored at $-80^{\circ} \mathrm{C}$ in deep frozen making until RNA isolation.

\subsection{RNA Isolation}

After approximately 50 to $100 \mathrm{mg}$ which tissues removed from RNA later solution was dried with blotting paper. The dried tissues were collected into $1.5 \mathrm{ml}$ micro centrifuge tubes containing $1 \mathrm{ml}$ Trizol reagent and then it was homogenized using a sterile steel balls in the homogenizer. The homogenized samples were incubated 5 minutes at room temperature and centrifuged at $12,000 \times \mathrm{g}$ and the supernatants were centrifuged for 2 minutes was transferred to a new tube. By adding $0.2 \mathrm{ml}$ chloroform was vortexed and incubated for $2-3$ minutes at 
room temperature. Samples were centrifuged at $12,000 \times \mathrm{g}$ for 15 minutes. The supernatant was transferred to a new tube and added onto $0.5 \mathrm{ml}$ of isopropyl alcohol. Samples were incubated at $15^{\circ} \mathrm{C}-30^{\circ} \mathrm{C}$ for 10 minutes and were centrifuged at $12,000 \times \mathrm{g}$ at $+4^{\circ} \mathrm{C}$ for 10 minutes. Supernatants were removed completely. RNA pellet was first washed with $1 \mathrm{ml} 75 \%$ ethanol. This washing procedure was repeated and the remaining ethanol was all removed. RNA pellet was exposed to air drying process for 5 - 10 minutes. It was diluted with DNase/ RNase-free water and was stored at $-80^{\circ} \mathrm{C}$ until cDNA obtained.

\subsection{Determination of RNA Concentration}

The amount of isolated RNA was measured using a Qubit device (Invitrogen, Carlsbad, CA). RNA pool was created according to the values of 4 groups measured by the Qubit device.

\subsection{Synthesis of cDNA}

cDNA synthesis from RNA sample was performed using the High Capacity cDNA synthesis kit.

\subsection{Real Time-PCR}

The obtained cDNAs, to investigate the gene expression of HSP90, $\mathrm{NF}_{\mathrm{\kappa}} \mathrm{B}$ and CAV-1 by using Tag Man expression assays (Invitrogen, Carlsbad, CA) were analyzed with ABI Prism 7500 Fast Real Time PCR (Applied Biosystems, Foster City, CA). 3 gene expressions on the 4 groups were compared using $2^{-\Delta \Delta} \mathrm{CT}$ values.

\subsection{ELISA}

Tissue ADMA, TLR-4, Rhokinase and the NADPH oxidase levels were measured by ELISA method. ADMA, TLR4, Rho Kinase and NADPH oxidase measurements in tissue samples from rats, were determined by ELISA kits according to protocol of commercial firms (Eastbiopharma, Cat No: CK-E90206-Ref: E20121120049-Lot: 20121120; Sunred, Cat No: 201110081-Ref: D2E201110081Lot: 201303; Eastbiopharma, Cat No: CK-E90094; Cusabio, Cat No: CSBEL015959 RA-Lot No: 24069902, respectively).

\subsection{Statistical Analysis}

Data are expressed as mean \pm SEM of the number (n) of experiments; A $P$-value of $<0.05$ was considered to be statistically significant. To determine the statistical significance of the data, computer software program was used. Mann Whitney $U$ test was used for evaluation of statistical differences after Kruskal Wallis.

\section{Results}

1. Blood Pressure: Mean blood pressure (MBP), systolic blood pressure (SBP) and diastolic blood pressure (DBP) values are summarized in Table 1. Between 
Table 1. Effects of Novokinin on Blood Pressure (mmHg). ${ }^{\text {a }}$ : Significantly different from IR group $(p<0.05)$. Sham $(C)$, Novokinin $(N)$, Ischemia Reperfusion (IR), IR + Novokinin (IRN). MBP: Mean Blood Pressure, SBP: Systolic Blood Pressure and DBP: Diastolic Blood Pressure.

\begin{tabular}{|c|c|c|c|c|c|c|c|}
\hline Groups & $\mathrm{BP}$ & Basal & $\begin{array}{c}\text { Before } \\
\text { ischemia }\end{array}$ & $\begin{array}{l}\text { Onset of } \\
\text { ischemia }\end{array}$ & $\begin{array}{c}\text { End of } \\
\text { ischemia }\end{array}$ & $\begin{array}{c}\text { Onset of } \\
\text { reperfusion }\end{array}$ & $\begin{array}{c}\text { End of } \\
\text { reperfusion }\end{array}$ \\
\hline \multirow{4}{*}{ IR } & SBP & $145 \pm 4$ & & $133 \pm 5$ & $130 \pm 3$ & $147 \pm 6$ & $149 \pm 3$ \\
\hline & DBP & $82 \pm 4$ & & $77 \pm 3$ & $75 \pm 4$ & $84 \pm 4$ & $85 \pm 6$ \\
\hline & MBP & $105 \pm 1$ & & $99 \pm 3$ & $98 \pm 4$ & $110 \pm 4$ & $108 \pm 5$ \\
\hline & SBP & $145 \pm 6$ & $134 \pm 6$ & $122 \pm 4^{\mathrm{a}}$ & $119 \pm 5^{\mathrm{a}}$ & $134 \pm 4^{\mathrm{a}}$ & $143 \pm 4^{\mathrm{a}}$ \\
\hline \multirow{2}{*}{ IRN } & DBP & $79 \pm 5$ & $74 \pm 4$ & $72 \pm 3^{a}$ & $72 \pm 3$ & $77 \pm 6$ & $81 \pm 2$ \\
\hline & MBP & $106 \pm 4$ & $98 \pm 4$ & $93 \pm 3^{a}$ & $91 \pm 3^{a}$ & $99 \pm 4^{\mathrm{a}}$ & $106 \pm 1$ \\
\hline
\end{tabular}

groups, there was no difference in baseline MBP, SBP and DBP. Novokinin administration significantly decreased SBP values in N group compared with IRN group. SBP values were significantly lower in IR group than IRN group during both IR. Although DBP and MBP values were significantly lower in IRN group than IR group at the beginning of ischemia, MBP value was significantly lower at the end of ischemia and at the beginning of reperfusion (Table 1). 2. NFkB levels: $\mathrm{NF \kappa B}$ levels were determined as $1.1 \pm 0.3,1 \pm 0.2,2.2 \pm 0.3$ and $1.25 \pm 0.21$ in C, N, IR and IRN groups, respectively. NFkB levels increased significantly in IR group compared to $\mathrm{C}$ and $\mathrm{N}$ groups but significantly decreased with administration of Novokinin (Figure 1).

3. TLR-4 levels: TLR-4 levels were determined as $19 \pm 2,18 \pm 2,24 \pm 3$ and 20 \pm 1 in C, N, IR and IRN groups, respectively. TLR-4 levels increased in IR group compared to $\mathrm{C}$ group but significantly decreased with Novokinin administration (Figure 2).

4. HSP90 levels: HSP90 levels were determined as $1 \pm 0.2,1 \pm 0.3,1.5 \pm 0.2$ and $1.2 \pm 0.2$ in C, N, IR and IRN groups, respectively. Although HSP90 levels increased significantly in IR group compared with $\mathrm{C}$ and $\mathrm{N}$ groups, was significantly decreased by Novokinin application (Figure 3 ).

5. ADMA levels: ADMA levels were determined as $3.9 \pm 1.1,3.7 \pm 1.2,8.3 \pm$ 1.7and $7.6 \pm 1.5$ in C, N, IR and IRN groups, respectively. ADMA level increased significantly in IR group compared to $\mathrm{C}$ group, although it tended to decrease with administration of Novokinin, but this was not statistically significant (Figure 4).

6. CAV-1 levels: CAV-1 levels were determined as $1.1 \pm 0.12,1 \pm 0.19,0.8 \pm$ 0.2 and $1.3 \pm 0.25$ in C, N, IR and IRN groups, respectively. Decreased CAV-1 levels in the IR group increased with administration of Novokinin, but this was not statistically significant (Figure 5).

7. NADPH oxidase levels: NADPH oxidase levels were determined as $2948 \pm$ $100,2870 \pm 102,4821 \pm 180$ and $2858 \pm 200$ in C, N, IR and IRN groups, respectively. NADPH oxidase levels increased significantly in IR group compared to C group, this elevation significantly decreased with Novokinin administration 


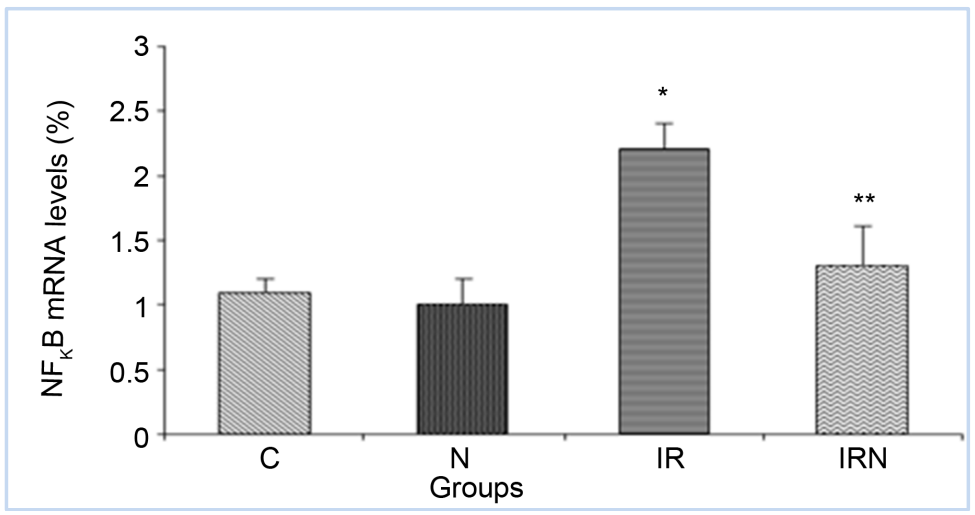

Figure 1. The effects of Novokinin on NFkB levels. ${ }^{*}$ : Significantly different from C and N groups, ${ }^{* *}$ : Significantly different from IR group, $(p<0.05)$. Sham $(C)$, Novokinin $(\mathrm{N})$, Ischemia Reperfusion (IR), IR + Novokinin (IRN).

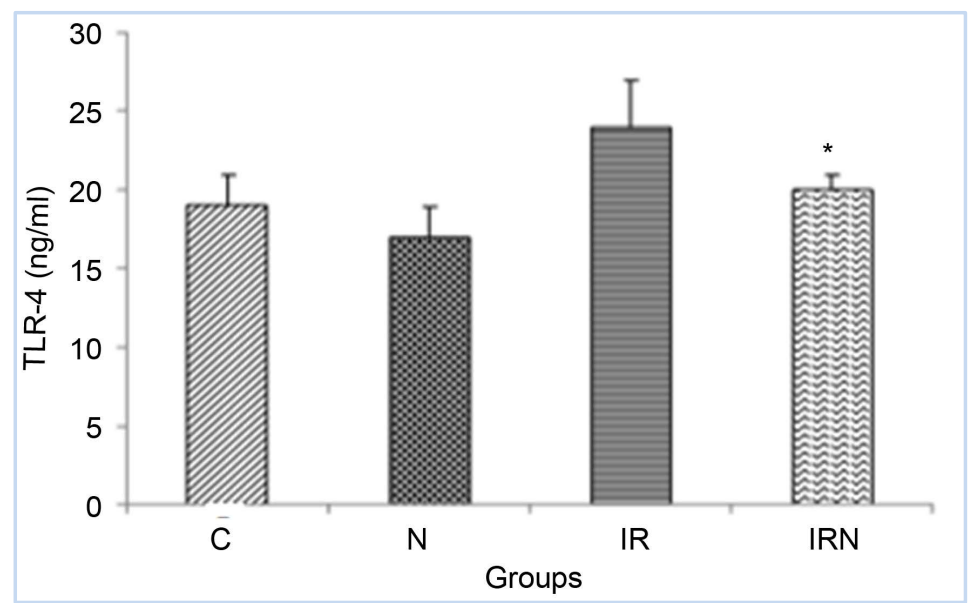

Figure 2. The effects of Novokinin on TLR-4 levels. ${ }^{*}$ : Significantly different from IR group, $(p<0.05)$. Sham $(\mathrm{C})$, Novokinin $(\mathrm{N})$, Ischemia Reperfusion (IR), IR + Novokinin (IRN).

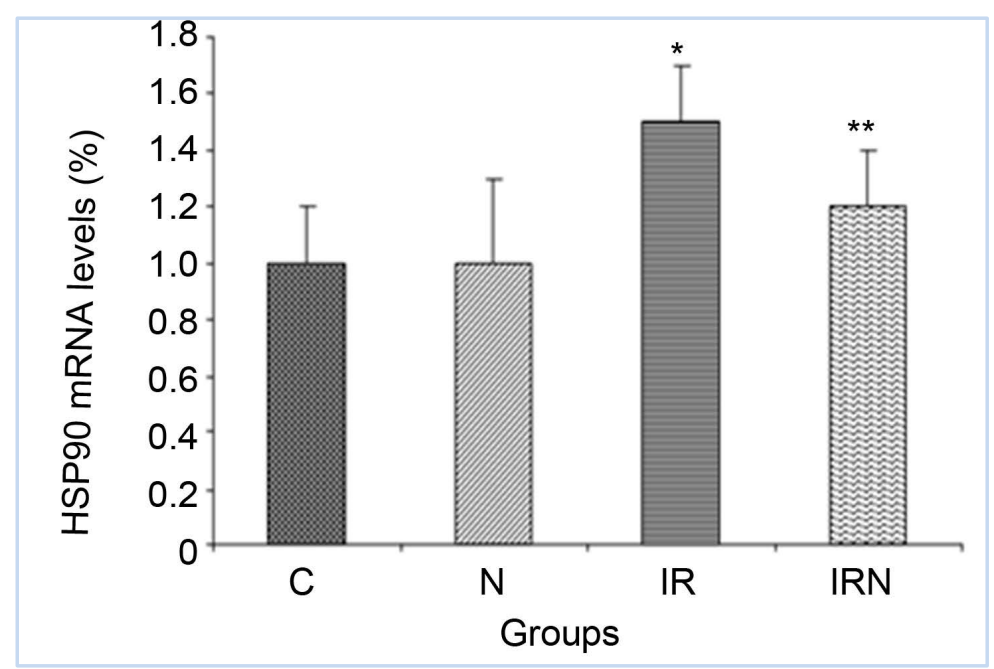

Figure 3. The effects of Novokinin on HSP90 levels. ${ }^{*}$ : Significantly different from C and N groups , ${ }^{* *}$ : Significantly different from IR group, $(p<0.05)$. Sham $(C)$, Novokinin $(N)$, Ischemia Reperfusion (IR), IR + Novokinin (IRN). 


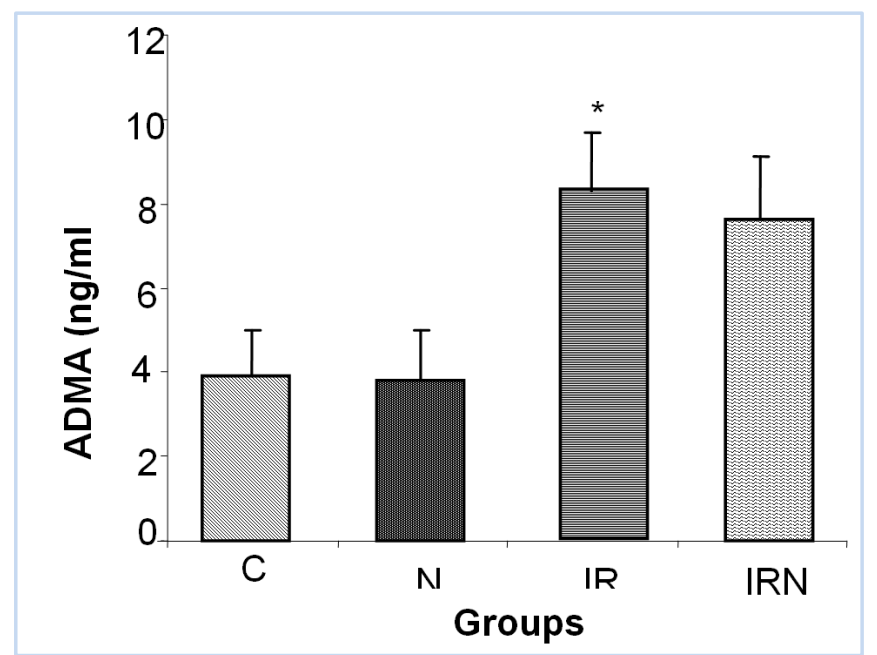

Figure 4. The effects of Novokinin on ADMA levels, *: Significantly different from C and $\mathrm{N}$ groups $(p<0.05)$. Sham $(\mathrm{C})$, Novokinin $(\mathrm{N})$, Ischemia Reperfusion (IR), IR + Novoki$\operatorname{nin}($ IRN).

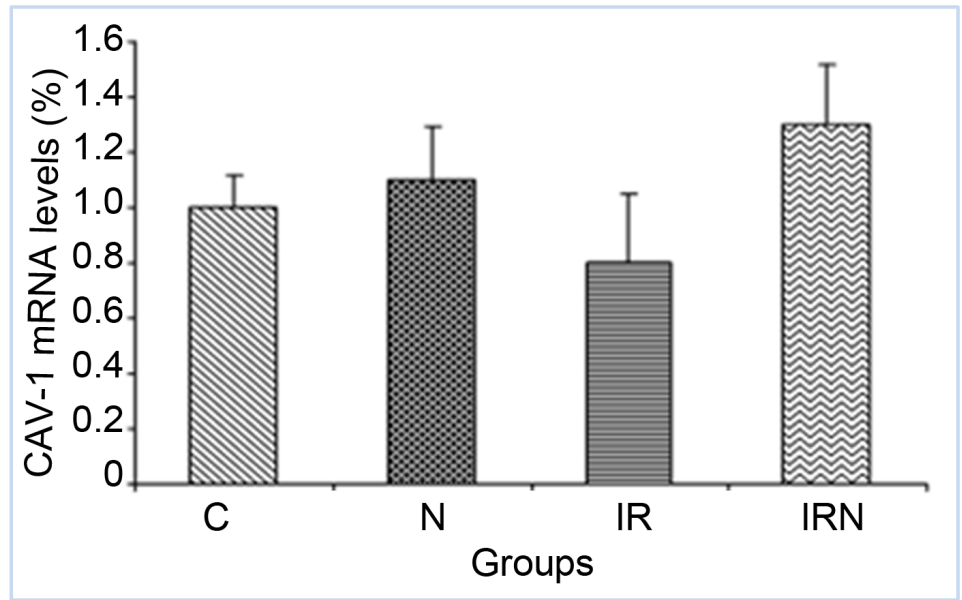

Figure 5. The effects of Novokinin on CAV-1 levels. Sham (C), Novokinin (N), Ischemia Reperfusion (IR), IR + Novokinin (IRN).

(Figure 6).

8. Rhokinase levels: Rhokinase levels were determined as $109 \pm 11,105 \pm 10$, $130 \pm 14$ and $117 \pm 16$ in C, N, IR and IRN groups, respectively. Increased Rhokinase levels in $\mathrm{C}$ and $\mathrm{N}$ groups compared to IR group decreased with Novokinin administration but this was not significant (Figure 7).

9. Evaluation of myocardial infarct size Infarct size due to IR were evaluated as $0.3939 \pm 0.05$ and $0.2339 \pm 0.04$ in IR and IRN groups, respectively. Infarct size was significantly reduced depending on Novokinin in IRN group compared to IR group (Figure 8).

\section{Discussion}

In our study, there was no difference between the groups in baseline BP values. Before the ischemia, during IR Novokinin, decreased MBP, SBP and DBP com- 


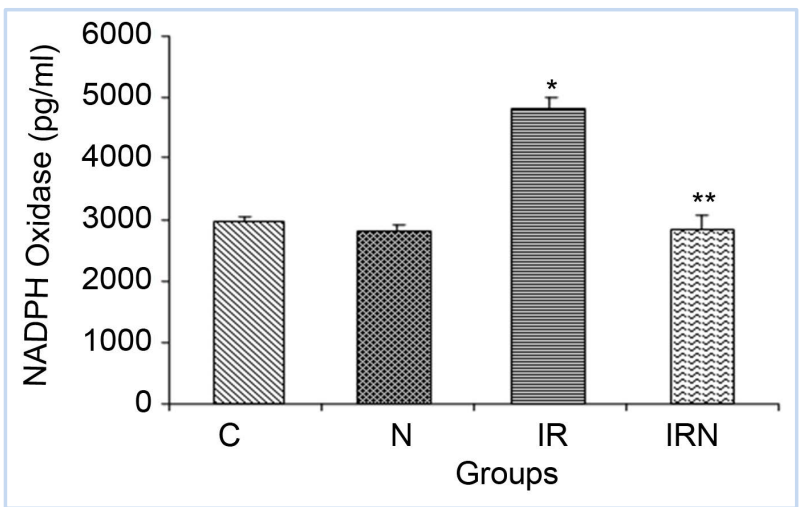

Figure 6. The effects of Novokinin on NADPH oxidase levels, ${ }^{*}$ : Significantly different from C group, ${ }^{* *}$ : Significantly different from IR group, $(p<0.05)$. Sham $(C)$, Novokinin (N), Ischemia Reperfusion (IR), IR + Novokinin (IRN).

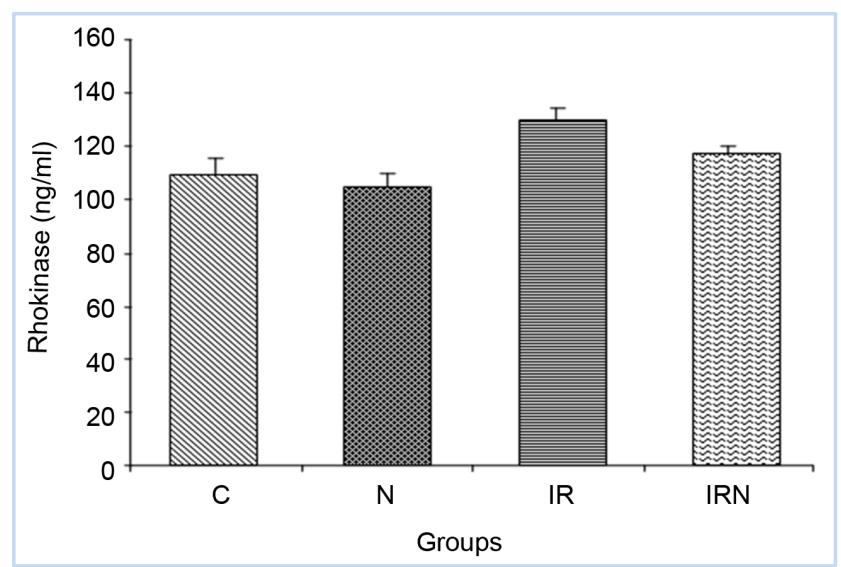

Figure 7. The effects of Novokinin on Rhokinase levels. Sham (C), Novokinin (N), Ischemia Reperfusion (IR), IR + Novokinin (IRN).

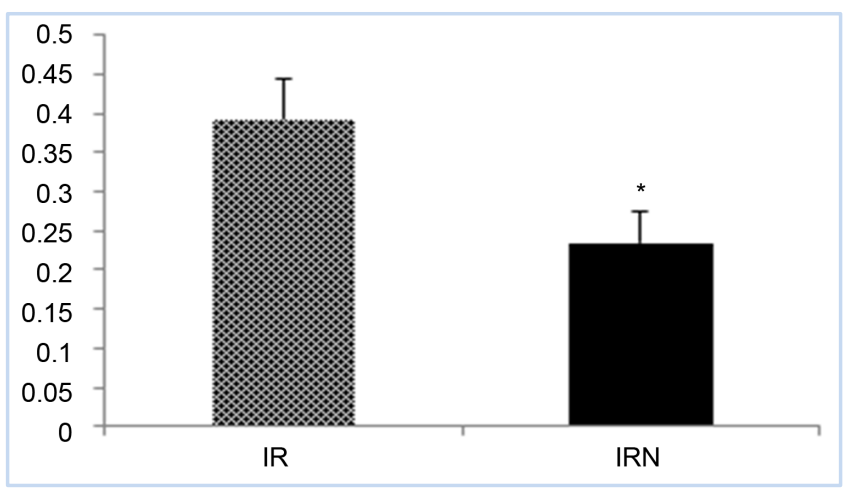

Figure 8. Effects of Novokinin on infarct size. ${ }^{*}$ :Significantly different from IR group, $(p$ $<0.05)$. Ischemia Reperfusion (IR), IR + Novokinin (IRN).

pared to IR group. Increased NFאB, NADPH oxidase, HSP90, TLR-4 levels and the infarct size due to IR significantly reduced with Novokinin administration. Increases in ADMA and Rhokinase values decreased with Novokinin application.

Administration of Novokinin significantly decreased SBP values during IR, 
DBP values in the onset of ischemia and MBP values except for the end of reperfusion compared to the IR group in our study. In another study with Novokinin, Novokinin significantly lowered SBP in spontaneously hypertensive rats (SHRs), at a dose of 0.03 and $0.1 \mathrm{mg} / \mathrm{kg}$ after intravenous (i.v.) and oral administration, respectively, and the hypotensive activity was blocked by PD123319, an antagonist of the AT2 receptor. In AT2 receptor-deficient mice, Novokinin did not reduce $\mathrm{BP}$. These results demonstrate that the hypotensive activity of Novokinin is mediated by the AT2 receptor [18]. The hypotensive activity of Novokinin in SHRs was completely blocked by Indomethacin and CAY10441, an inhibitor of cyclooxygenase and an antagonist of the prostaglandin IP receptor, respectively. These suggest that the hypotensive activity is mediated by prostacyclin and the IP receptor downstream of the AT2 receptor [18]. Novokinin dilated intact mesenteric artery isolated from SHRs dose-dependently above $10 \mu \mathrm{M}$. In endothelium-denuded artery, it did not show relaxing activity, indicating that the activity is mediated by an endothelium-derived relaxing factor. The relaxing effect of Novokinin was significantly blocked by AT2 receptor antagonist PD123319 (100 $\mu \mathrm{M})$ suggests that the effects of vasodilator was mediated AT2 receptor [19]. The results of our study are similar to the literatures which showing hypotensive effect of Novokinin.

NFkB levels were increased due to IR and significantly decreased with Novokinin administration in our study. Studies conducted with different experimental models support that NFkB protects cells from death. Loss of one of subunits of NFkB decreases cellular death in IR model [20]. Detection of NFkB activation in myocardial tissue of patients with heart failure due to various reasons makes us thought that inflammatory pathways in development of heart failure are acquired. It has been thought that NFkB promotes cardiovascular diseases via its proinflammatory, pro-adhesion and pro-oxidant gene transcription characteristics in arteries.

In our study, TLR-4 receptor level which increased due to IR was significantly decreased by Novokinin administration. Evidence concerning that TLR plays important roles in cardiovascular pathologies such as especially myocardial IR and atherosclerosis is getting increased [21]. It has been demonstrated that extracellular $\mathrm{O}_{2}{ }^{-}$which develops due to Xantine oxidase in IR injury activates neutrophils and induced neutrophil-related proinflammatory response occurs via TLR-4-related mechanisms [22]. In a study conducted with mice, high level of TLR-4 expression was determined in ventricular muscle 4 days after MI and it was reported that protection against myocardial inflammatory injury occurs in TLR-4 knock-out mice [23]. In a study conducted with carvedilol, it was expressed that inflammation was suppressed in infarct area due to inhibition of NFKB and TLR-4 expression and cardioprotection occurred [24]. These results make us thought that TLR-4 plays a proinflammatory role in myocardial IR.

HSP90 is regulator of eNOS and have shown its endothelial function, its role in NO release and its importance in terms of cardiovascular diseases. HSP90 levels increased due to IR, and significantly decreased with Novokinin administra- 
tion in our study. In a study which was conducted with male and female patients who had coronary artery disease, it was determined that HSP90 levels in arteries of both male and female patients were much less compared to healthy individuals [25]. In a study conducted with Brown Norway and Dahl S rats, however, it was determined that eNOS-dependent HSP90 levels increased 2-fold after ischemia in Brown Norway rats, a decrease of $63 \%$ in infarct size and when blockade was performed with L-NMA, the infarct size was enlarged. These results have led to thought of that HSP90-eNOS couple increases NO synthesis and this, in turn, is the mechanism underlying why Brown Norway rats are more resistant to ischemia [26]. In swine IR model to which HSP90 was transfected, it was determined that a decrease of $33 \%$ occurred in infarct size within the ischemic area in which HSP90 expression existed [7].

In our study, ADMA level which increased with IR, although it tended to decrease with administration of Novokinin, but this was not statistically significant. Mechanism of endothelial dysfunction induced by ADMA occurs through decrease of availability of vascular $\mathrm{NO}$ and increase of vascular $\mathrm{O}_{2}^{-}$levels [27]. In various experimental animal models and diseases, significant relationships have been established among increased ADMA level, increased oxidative stress and endothelial dysfunction. In a study containing 150 middle-aged individuals, it was demonstrated that increased ADMA levels increased risk for acute coronary artery disease 3.9-fold [28]. In mice for which different reperfusion times following 30-minute ischemia were applied, a significant accumulation of ADMA was determined in myocardial tissue and highest ADMA level was determined at $4^{\text {th }}$ hour of reperfusion. In mice for which oral L-Arginine was administered, reperfusion injury was decreased with $40 \%-50 \%$ at $4^{\text {th }}$ hour of reperfusion. It has been thought that ADMA exhibits its effects in reperfusion injury via decreasing activity and phosphorylation of eNOS, expression of adhesion molecules and leukocyte activity [29].

No change in CAV-1 level which increased with IR was determined by Novokinin administration. It has been observed that CAV-1 peptide is cardioprotective in myocardial IR and it exhibits this effect via an NO-mediated mechanism [30]. It has been determined that CAV-1 deficiency exacerbates cardiac dysfunction and decreases survival rate in rats that experienced myocardial infarction (MI] [8]. It has been reported that a decrease occurs in myocardial CAV-1 content following IR. CAV-1 peptides which were administration i.v. before 1 hour decreased neutrophilic infiltration and associated cardiac dysfunction. Also in the same study, it was determined that in the group to which CAV-1 was administered, basal NO release was increased 2.2-fold compared to the controls. It has been thought that CAV-1 decreases neutrophilic infiltration and cardiac dysfunction by increasing endothelial NO release. Superoxide $\left(\mathrm{O}_{2}^{-}\right)$inhibition and increased NO release in coronary vascular bed exhibit protective effect of CAV-1 in IR [30]. Modulation of endogenous CAV-1 expression has been shown in ischemic renal failure, MI and cerebral ischemia [8]. It has been thought that caveolins provide cardiac protection via its effects such as prevent- 
ing eNOS inhibition, accelerating NO release, decreasing $\mathrm{O}_{2}^{-}$production, improving post-ischemic left ventricular function and increasing superoxide dismutase (SOD) activity [31].

NADPH oxidase levels increased significantly due to IR, but significantly decreased with administration of Novokinin in this study. It has been observed that activity and expression of NADPH oxidase increase in experimental left ventricular hypertrophy [32] and MI [33]. Whereas inhibition of NADPH oxidase with Apocynin decreased myocardial oxidative stress and apoptosis, it improved post-MI cardiac functions [34]. It has been demonstrated that NADPH oxidase cause ROS production in epithelial cells, vascular smooth muscle cells, cardiomyocytes and fibroblasts [35]. AII can induce the enzyme NADPH oxidase via AT1 receptor and may exacerbate oxidative stress. Oxidative stress caused by interaction between RAAS and NADPH oxidase may have a key role in cardiovascular pathologies (atherosclerosis, diabetes, cardiac diseases, hypertension).

Rhokinase levels decreased with Novokinin administration but this decrement was not statistically significant our study. In an in vivo study condected with dogs, Fasudil, a Rhokinase inhibitor, which was administered prior to reperfusion depressed development of MI by preventing endothelial dysfunction. Fasudil exhibited its effect not only by preventing smooth muscle contractions but also by increasing eNOS synthesis [36]. In a study in which the role of RhoA and Rhokinase in acute myocardial IR injury was investigated, it was determined that RhoA expression was increased in ischemic myocardium with application of reperfusion for 24 hours following 30-minute ischemia and administration of oral Rhokinase inhibitor Y-27632 before 1 hour and following this, Rhokinase was activated. Y-27632 significantly inhibited Rhokinase activation which increased in IR and infarct size decreased by $41.1 \%$. In the same study, it was determined that post-ischemic cardiac functions were increased with Y-27632 and inflammatory substances and apoptosis which were increased with IR were decreased. These results make us thought that Rhokinase has a vital role in myocardial IR injury [37]. Excessive RhoA/Rhokinase activity may lead to a decrease in NO synthesis and to endothelial dysfunction and RhoA/Rhokinase inhibitors to reverse this have made RhoA/Rhokinase pathway an important therapeutic target in cardiovascular treatment [38].

Infarct size which developed due to IR was significantly reduced by Novokinin administration. In an in vivo rat myocardial IR model which was conducted with Captopril, an ACE inhibitor and Losartan and PD123319, AT1 and AT2 blockers, whereas Captopril and Losartan decrease infarct size by $30.50 \%$ and $37.75 \%$, respectively, it was not decreased by PD23319. It has been thought that AT2 receptor activation is potentially protective and may occur as against to effects of AT1 receptors [39]. In a study conducted with Candesartan which is an AT1 receptor antagonist and C21 which is non-peptide AT2 receptor agonist; it was determined that whereas no difference occurred between groups in terms of area of necrosis [40]. 


\section{Conclusion}

In conclusion, participation of Rhokinase, NADPH oxidase, ADMA, TLR-4, NFkB, CAV-1 and HSP90 levels to IR injury was determined in our study. It has been determined that Novokinin may contribute to protectiveness of reduction of BP during IR in infarct size, produce protective effects on endothelium via NO release by increasing eNOS activation with its effects on CAV-1 and HSP90 levels, have a protective role in cardiovascular diseases by preventing RAAS-induced oxidative stress in endothelium with decreasing NADPH oxidase level which is an effective enzyme in ROS, exhibit an improving effect on endothelial dysfunction by decreasing increased ADMA level which is an endogenous NOS inhibitor and increases with oxidative stress and by decreasing oxidative stress and has a significant role also on cardiac contractility and eNOS through decreasing of Rhokinase expression.

\section{References}

[1] Reiter, R.J. and Tan, D.X. (2003) Melatonin: A Novel Protective Agent against Oxidative Injury of the Ischemic-Reperfused Heart. Cardiovascular Research, 58, 10-19.

[2] Lefer, D.J. and Granger, D.N. (2000) Oxidative Stress and Cardiac Disease. American Journal of Medicine, 109, 315-323.

[3] Siemionow, M. and Arslan, E. (2004) Ischemia/Reperfusion Injury: A Review in Relation to Free Tissue Transfers. Microsurgery, 24, 468-475.

https://doi.org/10.1002/micr.20060

[4] Sydow, K. and Munzel, T. (2003) ADMA and Oxidative Stress. Atherosclerosis, 4, 41-51.

[5] Beg, A., Sha, W.C., Bronson, R., Ghosh, S. and Baltimore, D. (1995) Embryonic Lethality and Liver Degeneration in Mice Lacking the RelA Component of NF-Kappa B. Nature, 376, 167-170. https://doi.org/10.1038/376167a0

[6] Li, Y.W., Xie, G.R., Li, L., Jiang, Z.S., Yue, Z.S. and Pan, Z.Y. (2015) The Effect of TLR4/MyD88/NF-kB Signaling Pathway on Proliferation and Apoptosis in Human Nasopharyngeal Carcinoma 5-8F Cells Induced by LPS. Journal of Clinical Otorhinolaryngology Head and Neck Surgery, 11, 1012-1015.

[7] Kupatt, C., Dessy, C., Hinkel, R., Raake, P., Daneau, G., Bouzin, C., Boekstegers, P. and Feron, O. (2004) Heat Shock Protein 90 Transfection Reduces Ischemia-Reperfusion-Induced Myocardial Dysfunction via Reciprocal Endothelial NO Synthase Serine 1177 Phosphorylation and Threonine 495 Dephosphorylation. Arteriosclerosis, Thrombosis, and Vascular Biology, 24, 1435-1441. https://doi.org/10.1161/01.ATV.0000134300.87476.d1

[8] Jasmin, J.F., Rengo, G., Lymperopoulos, A., Gupta, R., Eaton, G.J., Quann, K., Gonzales, D.M., Mercier, I., Koch, W.J. and Lisanti, M.P. (2011) Caveolin-1 Deficiency Exacerbates Cardiac Dysfunction and Reduces Survival in Mice with Myocardial Infarction. American Journal of Physiology Heart and Circulatory Physiology, 300, 1274-1281. https://doi.org/10.1152/ajpheart.01173.2010

[9] Takemoto, M., Sun, J., Hiroki, J., Shimokawa, H. and Liao, J.K. (2002) Rho-Kinase Mediates Hypoxia-Induced Downregulation of Endothelial Nitric Oxide Synthase. Circulation, 106, 57-62. https://doi.org/10.1161/01.CIR.0000020682.73694.AB

[10] Maxwell, S.R. and Lip, G.Y. (1997) Reperfusion İnjury: A Review of the Pathophy- 
siology, Clinical Manifestations and Therapeutic Options. International Journal of Cardiology, 58, 95-117.

[11] Schwartzman, R.A. and Cidlowski, J.A. (1993) Apoptosis: The Biochemistry and Molecular Biology of Programmed Cell Death. Endocrine Review, 14, 133-150.

[12] Reilly, P.M., Schiller, H.J. and Bulkley, G.B. (1991) Pharmacologic Approach to Tissue Injury Mediated by Free Radicals and Other Reactive Oxygen Metabolites. The American Journal of Surgery, 161, 488-503.

[13] Kılınç, K. and Kılınç, A. (2002) Oksijen Toksisitesinin Aracı Molekülleri Olarak Oksijen Radikalleri. Hacettepe Tip Dergisi, 33, 110-118.

[14] Johnston, C.I. (1994) Tissue Angiotensin Converting Enzyme in Cardiac and Vascular Hypertrophy, Repair, and Remodeling Clinical Conference. Hypertension, 23, 258-268. https://doi.org/10.1161/01.HYP.23.2.258

[15] Horiuchi, M., Akishita, M. and Dzau, V.J. (1999) Recent Progress in Angiotensin II Type 2 Receptor Research in the Cardiovascular System. Brief Review, 33, 613-621. https://doi.org/10.1161/01.hyp.33.2.613

[16] Unger, T. (1999) The Angiotensin Type 2 Receptor: Variations on an Enigmatic Theme. Journal of Hypertension, 17, 1775-1786. https://doi.org/10.1097/00004872-199917121-00001

[17] Ohinata, K., Fujiwata, Y., Shingo, F., Masaru, I., Masatsugu, H. and Yoshikawa, M. (2009) Orally Administered Novokinin, an Angiotensin AT2 Receptor Agonist, Suppresses Food Intake via Prostaglandin E2-Dependent Mechanism in Mice. Peptides, 30, 1105-1108.

[18] Yamada, Y., Yamauchi, D., Usui, H., Zhao, H., Yokoo, M., Ohinata, K., Iwai, M., Horiuchi, M. and Yoshikawa, M. (2008) Hypotensive Activity of Novokinin, a Potent Analogue of Ovokinin(2-7), Is Mediated by Angiotensin AT(2) Receptor and Prostaglandin IP Receptor. Peptides, 29, 412-418.

[19] Yamada, Y., Yamauchi, D., Yokoo, M., Ohinata, K., Usui, H. and Yoshikawa, M. (2008) Potent Hypotensive Peptide, Novokinin, Induces Relaxation by AT2- and IP-Receptor-Dependent Mechanism in the Mesenteric Artery from SHRs. Bioscience, Biotechnology, and Biochemistry, 72, 257-259. https://doi.org/10.1271/bbb.70638

[20] Bond, M., Fabunmi, R., Baker, A. and Newby, A. (1998) Synergistic Upregulation of Metalloproteinase-9 by Growth Factors and Inflammatory Cytokines; An Absolute Requirement for Transcription Factor NF-Kappa B. FEBS Letters, 435, 29-34.

[21] Vallejo, J.G. (2011) Role of Toll-Like Receptors in Cardiovascular Diseases. Clinical Science, 121, 1-10. https://doi.org/10.1042/CS20100539

[22] Lorne, E., Zmijewski, J.W., Zhao, X., Liu, G., Tsuruta, Y., Park, Y.J., Dupont, H. and Abraham, E. (2008) Role of Extracellular Superoxide in Neutrophil Activation: Interactions between Xanthine Oxidase and TLR4 Induce Proinflammatory Cytokine Production. American Journal of Physiology: Cell Physiology, 294, 985-993. https://doi.org/10.1152/ajpcell.00454.2007

[23] Timmers, L., Sluijter, J.P., van Keulen, J.K., Hoefer, I.E., Nederhoff, M.G., Goumans, M.J., Doevendans, P.A., van Echteld, C.J., Joles, J.A., Quax, P.H., Piek, J.J., Pasterkamp, G. and de Kleijn, D.P. (2008) Toll-Like Receptor 4 Mediates MalAdaptive Left Ventricular Remodeling and Impairs Cardiac Function after Myocardial Infarction. Circulation Research, 102, 257-264. https://doi.org/10.1161/CIRCRESAHA.107.158220

[24] Liu, C.C., Huang, Y., Zhang, J.H., Xu, Y. and Wu, C.H. (2013) Effect of Carvedilol on Cardiac Dysfunction 4 Days after Myocardial Infarction in Rats: Role of Toll-Like Re- 
ceptor 4 and $\beta$-Arrestin 2. European Review for Medical and Pharmacological Sciences, 17, 2103-2110.

[25] Paier, A., Agewall, S. and Kublickiene, K. (2009) Expression of Heat Shock Proteins and Nitrotyrosine in Small Arteries from Patients with Coronary Heart Disease. Heart Vessels, 24, 260-266. https://doi.org/10.1007/s00380-008-1117-y

[26] Shi, Y., Hutchins, W. and Ogawa, H. (2005) Increased Resistance to Myocardial Ischemia in the Brown Norway vs. Dahl S Rat: Role of Nitric Oxide Synthase and Hsp90. Journal of Molecular and Cellular Cardiology, 38, 625-635.

[27] Richter, B., Niessner, A., Penka, M., Grdić, M., Steiner, S., Strasser, B., Ziegler, S., Zorn, G., Maurer, G., Simeon-Rudolf, V., Wojta, J. and Huber, K. (2005) Endurance Training Reduces Circulating ADMA and MPO Levels in Persons at Risk of Coronary Events. Thrombosis and Haemostasis, 94, 1306-1311.

[28] Valkonen, V.P., Päivä, H., Salonen, J.T., Lakka, T.A., Lehtimäki, T., Laakso, J. and Laaksonen, R. (2001) Risk of Acute Coronary Events and Serum Concentration of Asymmetrical Dimethylarginine. The Lancet, 358, 2127-2128.

[29] Stühlinger, M.C., Conci, E., Haubner, B.J., Stocker, E.M., Schwaighofer, J., Cooke, J.P., Tsao, P.S., Pachinger, O. and Metzler, B. (2007) Asymmetric Dimethyl L-Arginine (ADMA) Is a Critical Regulator of Myocardial Reperfusion Injury. Cardiovascular Research, 75, 417-425.

[30] Young, L.H., Ikeda, Y. and Lefer, A.M. (2001) Caveolin-1 Peptide Exerts Cardioprotective Effects in Myocardial Ischemia-Reperfusion via Nitric Oxide Mechanism. American Journal of Physiology Heart and Circulatory Physiology, 280, 2489-2495.

[31] Chow, A.K., Daniel, E.E. and Schulz, R. (2010) Cardiac Function İs Not Significantly Diminished in Hearts Isolated from Young Caveolin-1 Knockout Mice. American Journal of Physiology Heart and Circulatory Physiology, 299, 1183-1189. https://doi.org/10.1152/ajpheart.01195.2009

[32] Li, J.M., Gall, N.P., Grieve, D.J., Chen, M. and Shah, A.M. (2002) Activation of NADPH Oxidase during Progression of Cardiac Hypertrophy to Failure. Hypertension, 40, 477-484. https://doi.org/10.1161/01.HYP.0000032031.30374.32

[33] Fukui, T., Yoshiyama, M., Hanatani, A., Omura, T., Yoshikawa, J. and Abe, Y. (2001) Expression of p22phox and gp91phox, Essential Components of NADPH Oxidase, Increases after Myocardial Infarction. Biochemical and Biophysical Research Communications, 281, 1200-1206.

[34] Qin, F., Simeone, M. and Patel, R. (2007) Inhibition of NADPH Oxidase Reduces Myocardial Oxidative Stres and Apoptosis and Improves Cardiac Function in Heart Failure after Myocardial Infarction. Free Radical Biology \& Medicine, 43, 271-281.

[35] Xiao, L., Pimentel, D.R., Wang, J., Singh, K., Colucci, W.S. and Sawyer, D.B. (2002) Role of Reactive Oxygen Species and NAD(P)H Oxidase in alpha(1)-Adrenoceptor Signaling in Adult Rat Cardiac Myocytes. American Journal of Physiology Heart and Circulatory Physiology, 282, 926-934.

https://doi.org/10.1152/ajpcell.00254.2001

[36] Dong, M., Yan, B.P., Liao, J.K., Lam, Y.Y., Yip, G.W. and Yu, C.M. (2010) Rho-Kinase Inhibition: A Novel Therapeutic Target for the Treatment of Car-diovascular Diseases. Drug Discovery Today, 15, 622-629.

[37] Bao, W., Hu, E., Tao, L., Boyce, R., Mirabile, R., Thudium, D.T., Ma, X.L., Willette, R.N. and Yue, T.L. (2004) Inhibition of Rho-Kinase Protects the Heart against Ischemia/Reperfusion Injury. Cardiovascular Research, 61, 548-558.

[38] Zhou, Q. and Liao, J.K. (2009) Rho Kinase: An Important Mediator of Athe-rosclerosis and Vascular Disease. Current Pharmaceutical Design, 15, 3108-3115. https://doi.org/10.2174/138161209789057986 
[39] Parlakpinar, H., Ozer, M.K. and Acet, A. (2011) Effects of Captopril and Angiotensin II Receptor Blockers (AT1, AT2) on Myocardial Ischemia-Reperfusion Induced Infarct Size. Cytokine, 56, 688-694.

[40] Jehle, A.B., Xu, Y., Dimaria, J.M., French, B.A., Epstein, F.H., Berr, S.S., Roy, R.J., Kemp, B.A., Carey, R.M. and Kramer, C.M. (2012) A Nonpeptide Angiotensin II Type 2 Receptor Agonist Does Not Attenuate Postmyocardial Infarction Left Ventricular Remodeling in Mice. Journal of Cardiovascular Pharmacology, 59, 363-368. https://doi.org/10.1097/FJC.0b013e3182444110

\section{Scientific Research Publishing}

Submit or recommend next manuscript to SCIRP and we will provide best service for you:

Accepting pre-submission inquiries through Email, Facebook, LinkedIn, Twitter, etc. A wide selection of journals (inclusive of 9 subjects, more than 200 journals)

Providing 24-hour high-quality service

User-friendly online submission system

Fair and swift peer-review system

Efficient typesetting and proofreading procedure

Display of the result of downloads and visits, as well as the number of cited articles Maximum dissemination of your research work

Submit your manuscript at: http://papersubmission.scirp.org/

Or contact jbise@scirp.org 